\title{
Stripping Voltammetric Determination of Timolol Drug in Pharmaceuticals and Biological Fluids
}

\author{
Ali F. Al-Ghamdi \\ Department of Chemistry, College of Science, Taibah University, Madinah, Saudi Arabia \\ E-mail:aghamdi@taibahu.edu.sa \\ Received March 13, 2011; revised April 29, 2011; accepted May 3, 2011
}

\begin{abstract}
A sensitive and reliable stripping voltammetric method was developed to determine timolol drug. This method is based on the adsorptive accumulation of the drug at a hanging mercury drop electrode (HMDE) and then a negative sweep was initiated, which yield a well defined cathodic peak at $-850 \mathrm{mV}$ versus $(\mathrm{Ag} / \mathrm{AgCl})$ silver reference electrode. To achieve high sensitivity, various experimental and instrumental variables were investigated such as supporting electrolyte, $\mathrm{pH}$, accumulation time and potential, scan rate, frequency, pulse amplitude, convection rate and working electrode area. The monitored adsorptive current was directly proportional to the concentration of timolol and it shows a linear response in the range from $1 \times 10^{-7}$ to $1.5 \times$ $10^{-6} \mathrm{~mol} \cdot \mathrm{l}^{-1}$ of this drug (correlation coefficient $\left.=0.998\right)$ and the detection limit $(\mathrm{S} / \mathrm{N}=3)$ is $1.26 \times 10^{-9}$ $\mathrm{mol} \cdot \mathrm{l}^{-1}$ at an accumulation time of $30 \mathrm{sec}$. The developed adsorptive stripping voltammetry (AdSV) procedure shows a good reproducibility, the relative standard deviation $\mathrm{RSD} \%(n=8)$ at a concentration level of 1 $\times 10^{-6} \mathrm{~mol} \cdot \mathrm{l}^{-1}$ of timolol was $0.13 \%$, whereas the method accuracy was indicated via the mean recovery of $110 \% \pm 1.414$. Possible interferences by several substances usually present in the pharmaceutical formulations have been also evaluated. The applicability of this approach was illustrated by the determination of the drug in pharmaceutical preparation and biological fluids such as serum and urine.
\end{abstract}

Keywords: Stripping Voltammetry, HMDE, Timolol, Urine, Serum

\section{Introduction}

Of the most commonly used instrumental techniques, electroanalytical approach is the one of choice, and stripping voltammetric method has provoked particular interest because it is currently the most sensitive and widely used electrochemical technique. Its possibility of applications cover many fields ranging from environment, pharmaceutical and clinical to food and industrial samples. Many of the adsorptive stripping voltammetric (adsv) approach features such as sensitivity, selectivity, simplicity and versatility attributed to the combination of an effective preconcentartion step based on non-electrolytic adsorptive accumulation process with an advanced measurement procedures such as differential pulse (DP) or square wave (SW) [1-5]. Unlike conventional stripping approaches (anodic and cathodic stripping voltammetry), which are based on an electrolytic nature of preconcentration step, adsorptive stripping voltammetric approach in contrast is based on adsorptive accumulation of the analyte on the electrode at open circuit with no charge transferred. Consequently, for a wide range of surface-active organic and inorganic species, which cannot be preconcentrated electroanalytically, the adsorption approach allows these analytes to be interfacially accumulated on the electrode and hence analysed. There have been many reviews devoted to emphasize and illustrate the wide spectrum and scope of adsorptive stripping vol-tammetric applications and potentialities in the analysis of metal ions [6,7] organic analytes [8,9] and pharma-ceutical drugs and biomedical compounds, such as, the anti-Inflammatory drug Lornoxicam, the antidepressant drug sulpiride and Josamycin, a Macrolide Antibiotic $[10-14]$. Timolol was the first beta $(\beta)$ blocker to be used as an anti-glaucoma agent and to date remains as the standard because none of the newer $\beta$ blockers were found to be more effective. Timolol maleate is the generic name for (Ocumol 0.5, Timolo $0.5 \%, 5 \mathrm{mg} / \mathrm{ml}$ - Riyadh, Pharma-SA), an eye drop (ophthalmic solution) indicated for the treatment of elevated intraocular pressure for those patients with primary open-angle glaucoma and ocular hypertension. Timolol maleate should be used 
with care. It is important not to contaminate the solution, because this can cause infection and/or inflammation in the eye. If you are using more than one eye-drop medication, administration of the drugs should be spaced at least ten minutes apart to provide adequate time for absorption. Timolol is soluble in distilled water, its molecular weight is $316.421 \mathrm{~g} / \mathrm{mol}$ and systematic IUPAC name is (S)-1-(tert-butylamino)-3-[(4-morpholin-4-yl-1, 2,5-thiadiazol-3-yl)oxy]propan-2-ol[15,16]. The chemical structure of this drug and the mechanism for the electrochemical reduction process of its compound are shown in Scheme 1 (The mechanism proposed of electrochemical reduction for timolol drug). Timolol drug has been analysed in pharmaceutical formulations and biological samples by various analytical methods such as spectrophotometric [17-19], chromatographic [20,21], high performance liquid chromatography (HPLC) [22] and differential pulse voltammetric [23]. However, to the best of our knowledge, the square wave voltammetric behavior of timolol and thus its square-wave adsorptive stripping voltammetry (SW-adsv) have not been performed and reported so far. Consequently, the aim of this work was to develop more sensitive, reliable and simple $\mathrm{SW}$-adsv procedure for the determination of timolol drug in biological media and pharmaceutical formulations.

\section{Experimental}

\subsection{Apparatus}

All adsorptive stripping measurements were carried out with 797 VA computrace (Metrohm, Switzerland) in connection with Dell computer and controlled by VA computrace 2.0 control software. Stripping voltammograms were obtained via a hp color laserjet CP1215 printer. A conventional three electrode system was used in the hanging mercury drop electrode (HMDE) mode. $\mathrm{pH}$ values were measured with Hanna instruments $\mathrm{pH}$ 211 (Romania made) pH meter. The labofuge 200 instrument, Heraeus sepatech (Germany) was used for centrifuging of biological fluids to suite for stripping analysis.



Scheme 1. The mechanism proposed of electrochemical reduction for timolol drug.

\subsection{Reagents}

All chemicals used were of analytical reagent grade and were used without further purification. Timolol stock solution of $1 \times 10^{-2} \mathrm{~mol} \cdot 1^{-1}$ were prepared by dissolving the appropriate amount of this drug in distilled water in $10 \mathrm{ml}$ volumetric flask. This stock solution was stored in the dark and under refrigeration in order to minimize decomposition. Standard solutions of this drug with lower concentrations were prepared daily by diluting the stock solution with distilled water. Britton-Robinson supporting buffer ( $\mathrm{pH} \approx 2,0.04 \mathrm{M}$ in each constituent) was prepared by dissolving $2.47 \mathrm{~g}$ of boric acid in $500 \mathrm{ml}$ distilled water containing $2.3 \mathrm{ml}$ of glacial acetic acid and then adding $2.7 \mathrm{ml}$ of ortho-Phosphoric acid and diluting to $1 \mathrm{~L}$ with distilled water. In addition, phosphate supporting buffer $\left(0.1 \mathrm{M} \mathrm{NaH}_{2} \mathrm{PO}_{4}\right.$ and $\left.0.1 \mathrm{M} \mathrm{H}_{3} \mathrm{PO}_{4}\right)$ was prepared by dissolving $12 \mathrm{~g}$ of $\mathrm{NaH}_{2} \mathrm{PO}_{4}$ and $6.78 \mathrm{~g}$ of $\mathrm{H}_{3} \mathrm{PO}_{4}$ in $1000 \mathrm{ml}$ distilled water. Acetate supporting buffer $(0.02 \mathrm{M}$ in each constituent) was prepared by dissolving $1.68 \mathrm{~g}$ of sodium acetate in $500 \mathrm{ml}$ distilled water containing $1.12 \mathrm{ml}$ of acetic acid and diluting to $1 \mathrm{~L}$ with distilled water. Finally, carbonate supporting buffer $(0.1$ $\mathrm{M}$ in each constituent) was prepared by dissolving $10.6 \mathrm{~g}$ of sodium carbonate and $8.4 \mathrm{~g}$ of sodium hydrogen carbonate in $1000 \mathrm{ml}$ distilled water.

\subsection{Procedure}

The general procedure adopted for obtaining adsorptive stripping voltammograms was as follows: A $10 \mathrm{ml}$ aliquot of B-R supporting buffer (unless otherwise stated) at the desired $\mathrm{pH}$ (e.g. 3.5) was pipetted into a clean and dry voltammetric cell and the required standard solution of timolol was added. The test solution was purged with nitrogen for 5 minutes initially, while the solution was stirred. The accumulation potential of $-0.8 \mathrm{~V}$ vs. $\mathrm{Ag} / \mathrm{AgCl}$ was applied to a new mercury drop while the solution was stirred for 30 seconds. Following the preconcentration period, the stripping was stopped and after $20 \mathrm{sec}-$ onds had elapsed, cathodic scans were carried out over the range 0.0 to $-1.2 \mathrm{~V}$. All measurements were made at room temperature.

\section{Preliminary Observations}

When the differential pulse polarographic behavior was investigated for timolol drug in acetate buffer at $\mathrm{pH} 3.5$, a broad polarographic wave at $E_{p}=-0.850 \mathrm{~V}$ was observed and this obtained polarographic wave, as shown in Figure 1 (Differential Pulse Polarographic of $5 \times 10^{-5}$ $\mathrm{mol} \cdot \mathrm{l}^{-1}$ Timolol in $\mathrm{pH} 3.5$ Acetate buffer, scan rate 25 $\mathrm{mV} \cdot \mathrm{s}^{-1}$ ), is probably due to the electrochemical reduction 




Figure 1. Differential Pulse Polarographic of $5 \times 10^{-5} \mathrm{~mol} \cdot \mathrm{l}^{-1}$ Timolol in pH 3.5 Acetate buffer, scan rate $25 \mathrm{mV} \cdot \mathrm{s}^{-1}$.

of the double bond $(-\mathrm{N}=\mathrm{C})$ as shown in the previous scheme1, which including a proposed mechanism for the electrochemical reduction of this drug. This mechanism suggesting that the electrochemical reaction is an irreversible process, an assumption which was confirmed by cyclic voltammetric measurement at a scan rate of 50 $\mathrm{mV}^{-1}$ of timolol in acetate buffer ( $\mathrm{pH}$ 3.5) as shown in Figure 2 (Cyclic voltammogram of $5 \times 10^{-5} \mathrm{~mol} \cdot l^{-1} \mathrm{Ti}-$ molol in $\mathrm{pH} 3.5$ Acetate buffer, scan rate $50 \mathrm{mV} \cdot \mathrm{s}^{-1}$ ).

In order to obtain a voltammetric peak with better definition and higher sensitivity, a HMDE was used to study the adsorptive prosperities of timolol compound. The AdSV behavior of the drug was investigated in various supporting electrolytes at different $\mathrm{pH}$ values. This Drug compound yielded a well-developed and defined AdSV peak corresponding to the electroactive $-\mathrm{N}=\mathrm{C}$ at peak potential of $-0.85 \mathrm{~V}$. A typical adsorptive stripping voltammogram for $5 \times 10^{-7} \mathrm{~mol} \cdot \mathrm{l}^{-1}$ timolol in acetate buffer is shown in Figure 3 (SW-AdSV voltammogram

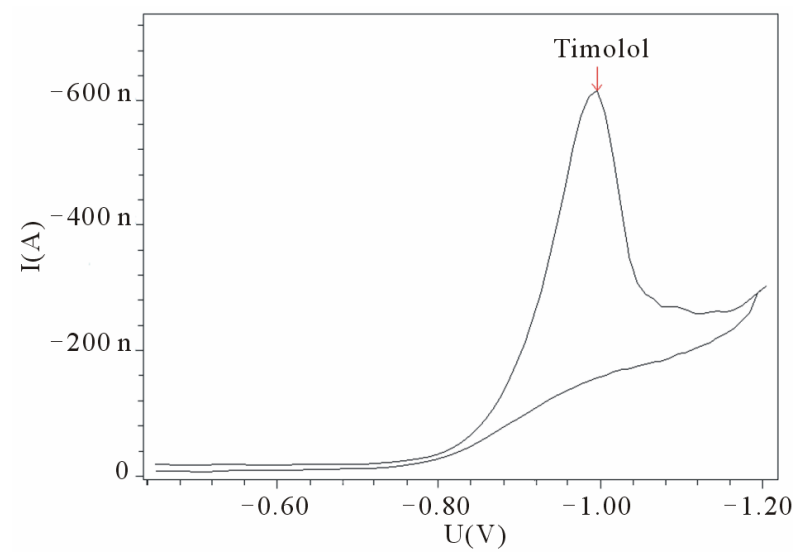

Figure 2. Cyclic voltammogram of $5 \times 10^{-5} \mathrm{~mol} \cdot \mathrm{l}^{-1}$ Timolol in pH 3.5 Acetate buffer, scan rate $50 \mathrm{mV} \cdot \mathrm{s}^{-1}$.

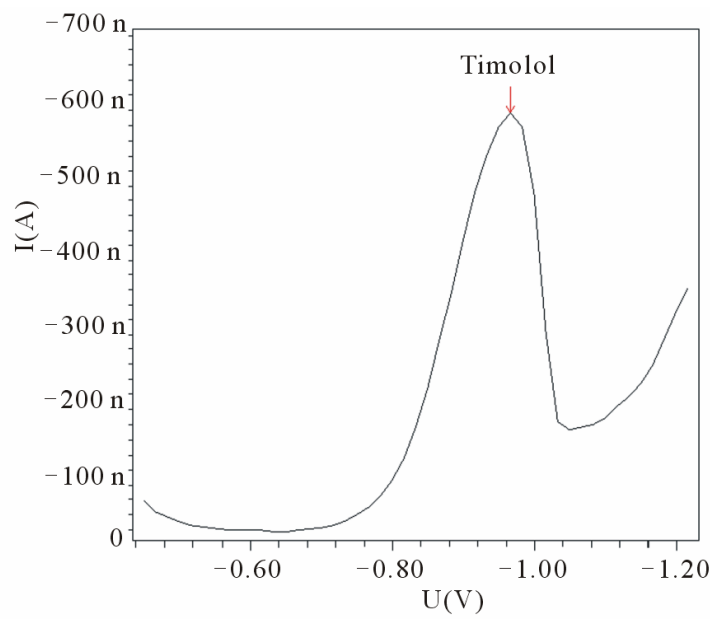

Figure 3. SW-AdSV voltammogram of $5 \times 10^{-7} \mathrm{~mol} \cdot \mathrm{l}^{-1} \mathrm{Ti}-$ molol in pH 3.5 Acetate buffer. Accumulation time $30 \mathrm{sec}$, accumulation potential $-0.8 \mathrm{~V}$ and scan rate $250 \mathrm{mV} \cdot \mathrm{s}^{-1}$.

of $5 \times 10^{-7} \mathrm{~mol} \cdot \mathrm{l}^{-1}$ Timolol in $\mathrm{pH} 3.5$ Acetate buffer. Accumulation time $30 \mathrm{sec}$, accumulation potential $-0.8 \mathrm{~V}$ and scan rate $250 \mathrm{mV} \cdot \mathrm{s}^{-1}$ ), which illustrates a well observed electrochemical peak indicating a strong and readily adsorption process at the surface of the working electrode.

\subsection{Parameters Affecting the Adsorptive Stripping Response}

\subsubsection{Effect of Supporting Electrolyte and $\mathrm{pH}$}

The nature and acidity of the supporting buffer are some of the most important factors which strongly influence the stability of the analyte and its cathodic reduction and adsorption processes. Among the various investigated buffers (B-R, acetate, carbonate and phosphate) the best voltammetric signal in terms of sensitivity (peak height) and resolution (peak shape) have been secured using acetate buffer. In addition, when the AdSV peak current was measured as a function of $\mathrm{pH}$ over 2-6 range, the stripping voltammetric signal increased steadily over the acidic region and the peak current reached its maximum value at $\mathrm{pH} 3.5$ which was selected as optimal value for subsequent studies. It is noteworthy that when more than 3.5 acetate supporting electrolyte was used, timolol was barely detectable and nearly no stripping voltammetric signal was observed. The variation of AdSV peak current with $\mathrm{pH}$, obtained for $1 \times 10^{-6} \mathrm{~mol} \cdot 1^{-1}$ Timolol drug concentration accumulated for $30 \mathrm{sec}$ is exhibited in Figure 4 (Effect of $\mathrm{pH}$ on AdSV peak current of $1 \times 10^{-6} \mathrm{M}$ Timolol at Acetate buffer).

\subsubsection{Effect of Accumulation Time and Potential}

Preconcentration of the analyzed drug on the surface of the working electrode (HMDE) is one of the essential 


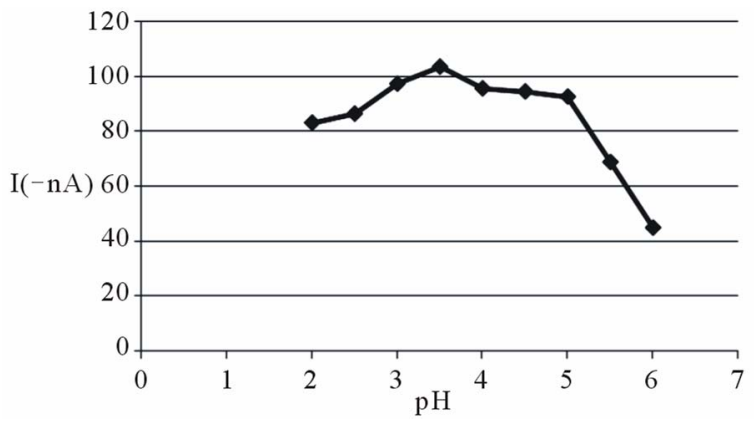

Figure 4. Effect of pH on AdSV peak current of $1 \times 10^{-6} \mathrm{M}$ Timolol at Acetate buffer.

conditions for highly sensitive determinations. Variation of the accumulation time over $0-150 \mathrm{sec}$ period for $1 \times$ $10^{-6} \mathrm{~mol} \cdot \mathrm{l}^{-1}$ timolol drug solution at a preconcentration potential of $0.0 \mathrm{~V}$, showed a gradual enhancement for the monitored peak current over the range $0-30 \mathrm{sec}$. The dependence of peak current on accumulation time is presented in Figure 5 (Effect of accumulation time on AdSV peak current of $1 \times 10^{-6} \mathrm{M}$ Timolol in $\mathrm{pH} 3.5$ Acetate buffer). The proportional relationship was nearly ob- served up to $30 \mathrm{sec}$ and then it became virtually curved and leveled off owing to the saturation of the hanging mercury drop by the analyte. For further experiments an accumulation time of $30 \mathrm{sec}$ was selected as optimal because it provided relatively high peak current with adequate practical time. The variation of accumulation time did not produce significant shifts in peak potential value.

In addition, as can be seen from Figure 6 (Effect of accumulation potential on AdSV peak current of $1 \times 10^{-6}$ $\mathrm{M}$ Timolol in $\mathrm{pH} 3.5$ Acetate buffer and accumulation time $30 \mathrm{sec}$ ), when the influence of accumulation potential on the monitored electrochemical response was examined over the -0.8 to $+0.8 \mathrm{~V}$ range at $30 \mathrm{sec}$ preconcentration time, the peak current was directly reached its maximum value at $E_{p}=-0.8 \mathrm{~V}$ then it decreased sharply after potential $-0.8 \mathrm{~V}$. Thus, $E_{a c c}=0.8 \mathrm{~V}$ will be adopted as optimum operational value for the following works as it ensured the highest AdSV signal.

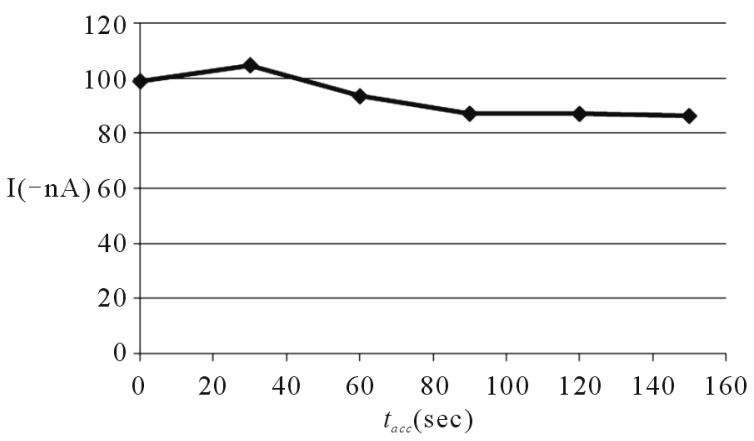

Figure 5. Effect of accumulation time on AdSV peak current of $1 \times 10^{-6} \mathrm{M}$ Timolol in $\mathrm{pH} 3.5$ Acetate buffer.

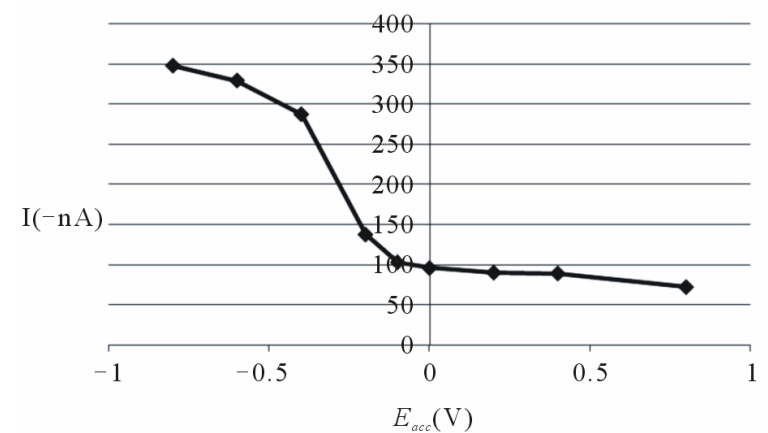

Figure 6. Effect of accumulation potential on AdSV peak current of $1 \times 10^{-6} \mathrm{M}$ Timolol in $\mathrm{pH} 3.5$ Acetate buffer and accumulation time $30 \mathrm{sec}$.

\subsubsection{Effect of Scan Rat}

The cathodic peak current of timolol drug was found to be forthwith proportional to the scan rate, particularly at low scan rate values, a phenomenon characterized for adsorbed materials [24]. When the stripping voltammetric peak current of $1 \times 10^{-6} \mathrm{~mol} \cdot \mathrm{l}^{-1}$ timolol drug in $\mathrm{pH} 3.5$ acetate buffer was measured over the range $10-300$ $\mathrm{mV} / \mathrm{s}$, it was found that peak height was observed in the scan rate $250 \mathrm{mV} / \mathrm{s}$ as it was shown in Figure 7 (Effect of scan rate on AdSV peak current of $1 \times 10^{-6} \mathrm{M}$ Timolol in $\mathrm{pH} 3.5$ Acetate buffer, accumulation time $30 \mathrm{sec}$ and accumulation potential $-0.8 \mathrm{~V}$ ). However, after this maximum value the peak current started to decrease directly with faster scan rate. Accordingly, $250 \mathrm{mV} / \mathrm{s}$ scan rate value was adopted as optimum condition for further investigations.

\subsubsection{Effect of Pulse Amplitude and Frequency}

In addition, the impact of varying the excitation wave pulse amplitude on the voltammetric current intensity was also evaluated. The effect of this operating variable was studied over the rang $10-120 \mathrm{mV}$ (see Figure 8: Effect of pulse amplitude on the peak current of $1 \times 10^{-6}$ M Timolol in $\mathrm{pH} 3.5$ Acetate buffer, accumulation time $30 \mathrm{sec}$, accumulation potential $-0.8 \mathrm{~V}$ and $250 \mathrm{mV} / \mathrm{s}$ scan

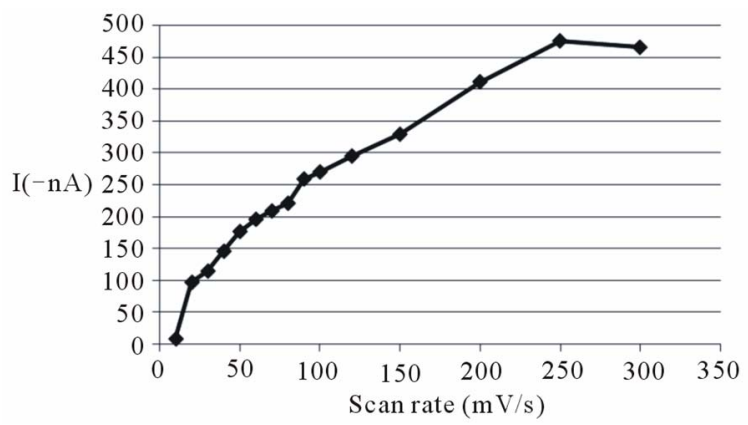

Figure 7. Effect of scan rate on AdSV peak current of $1 \times$ $10^{-6} \mathrm{M}$ Timolol in pH 3.5 Acetate buffer, accumulation time $30 \mathrm{sec}$ and accumulation potential $\mathbf{- 0 . 8} \mathrm{V}$. 


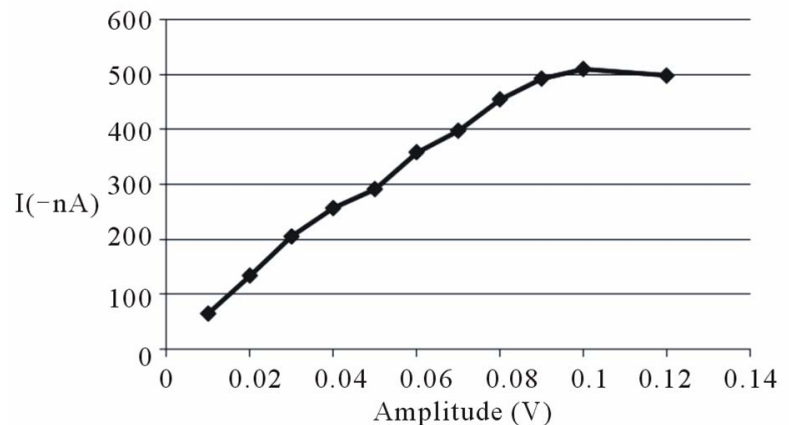

Figure 8. Effect of pulse amplitude on the peak current of 1 $\times 10^{-6} \mathrm{M}$ Timolol in $\mathrm{pH} 3.5$ Acetate buffer, accumulation time $30 \mathrm{sec}$, accumulation potential $-0.8 \mathrm{~V}$ and $250 \mathrm{mV} / \mathrm{s}$ scan rate.

rate) and it was concluded that in order to assure maximum peak current, $100 \mathrm{mV}$ pulse amplitude was the ideal choice for this operational parameter. Moreover, varying the value of square wave frequency also plays an important role for the measured signal of square wave- adsorptive stripping voltammetric (SW-AdSV) approach. When the voltammetric peak current of $1 \times 10^{-6} \mathrm{~mol} \cdot \mathrm{l}^{-1}$ timolol drug in acetate buffer $\mathrm{pH} 3.5$ was measured over the range $10-50 \mathrm{~Hz}$, as in Figure 9 (Effect of frequency on the peak current of $1 \times 10^{-6} \mathrm{M}$ Timolol in $\mathrm{pH} 3.5$ Acetate buffer, accumulation time $30 \mathrm{sec}$, accumulation potential $-0.8 \mathrm{~V}$, Scan rate $250 \mathrm{mV} / \mathrm{s}$ and pulse amplitude $0.10 \mathrm{~V}$ ), it was found that peak height was observed at a low frequency $10-15 \mathrm{~Hz}$ only, after this value $(15 \mathrm{~Hz})$ the peak current started to decrease with increasing frequency. Accordingly, for farther work $15 \mathrm{~Hz}$ square wave frequency value was adopted.

\subsubsection{Effect of Instrumental Parameters}

The monitored adsorptive stripping voltammetry (AdSV) peak height could be further maximized by optimizing other experimental factors that can affect the adsorption



Figure 9. Effect of frequency on the peak current of $1 \times 10^{-6}$ $\mathbf{M}$ Timolol in pH 3.5 Acetate buffer, accumulation time 30 sec, accumulation potential $-0.8 \mathrm{~V}$, Scan rate $250 \mathrm{mV} / \mathrm{s}$ and pulse amplitude $0.10 \mathrm{~V}$. process of the formed drug. The influence of both the surface size of the mercury drop working electrode and electrode convection rate was also evaluated. An increase in the surface of the working electrode (over $0.15-0.60$ $\mathrm{mm}^{2}$ ) yielded, as expected, a linear enhancement in the analytical signal and did not affect the value of the stripping voltammetric potential. In addition, an increase in the stirring rate (raising it from 0.0 to $3000 \mathrm{rpm}$ ) yielded, a linear enhancement in the analytical signal from 0.0 to $2000 \mathrm{rpm}$, after that it is decreased and did not affect the value of the stripping voltammetric potential. Thus, for optimal sensitivity, $0.60 \mathrm{~mm}^{2}$ drop size and $2000 \mathrm{rpm}$ stirring speed were chosen for subsequent practical works (see Figures 10: Effect of electrode area on the peak current of $1 \times 10^{-6} \mathrm{M}$ Timolol in $\mathrm{pH} 3.5$ Acetate buffer, accumulation time $30 \mathrm{sec}$, accumulation potential $-0.8 \mathrm{~V}$, Scan rate $250 \mathrm{mV} / \mathrm{s}$, pulse amplitude $0.10 \mathrm{~V}$ and frequency $15 \mathrm{~Hz}$, Figure 11: Effect of convection rate on the peak current of $1 \times 10^{-6} \mathrm{M}$ Timolol in $\mathrm{pH} 3.5$ Acetate buffer, accumulation time $30 \mathrm{sec}$, accumulation potential $-0.8 \mathrm{~V}$, Scan rate $250 \mathrm{mV} / \mathrm{s}$, pulse amplitude $0.10 \mathrm{~V}$, frequency $15 \mathrm{~Hz}$ and drop size $0.6 \mathrm{~mm}^{2}$ ).

\subsection{Analytical Performance (Method Validation)}

Once the most ideal and suitable chemical conditions and instrumental parameters for the adsorptive determination were established, a calibration plot for the analyzed drug was recorded to estimate the analytical characteristics of the developed method.

\subsubsection{Calibration Graph}

Under the optimum conditions a very good linear correlation was obtained between the monitored voltammetric peak current and timolol concentration in the range $1 \times$ $10^{-7}-1.5 \times 10^{-6} \mathrm{~mol} \cdot \mathrm{l}^{-1}$, is constant in all measurements, (see Figure 12: SW-AdSV voltammogram for Timolol in acetate buffer, $\mathrm{pH}=3.5, T_{a c c}=30 \mathrm{sec}, E_{a c c}=-0.80 \mathrm{~V}$.

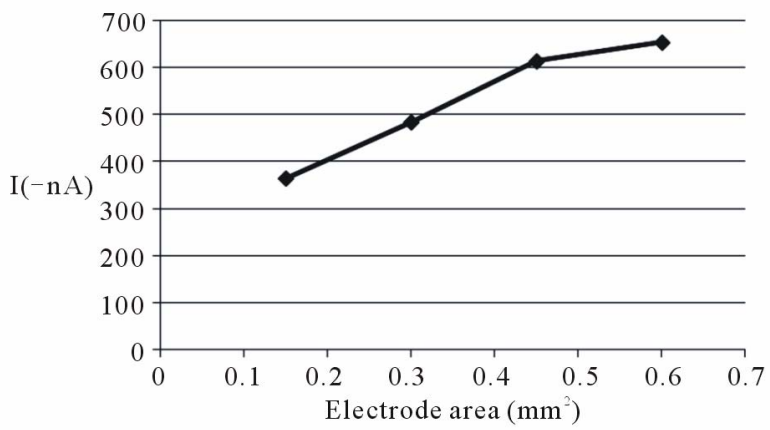

Figure 10. Effect of electrode area on the peak current of 1 $\times 10^{-6} \mathrm{M}$ Timolol in pH 3.5 Acetate buffer, accumulation time $30 \mathrm{sec}$, accumulation potential $-0.8 \mathrm{~V}$, Scan rate 250 $\mathrm{mV} / \mathrm{s}$, pulse amplitude $0.10 \mathrm{~V}$ and frequency $15 \mathrm{~Hz}$. 


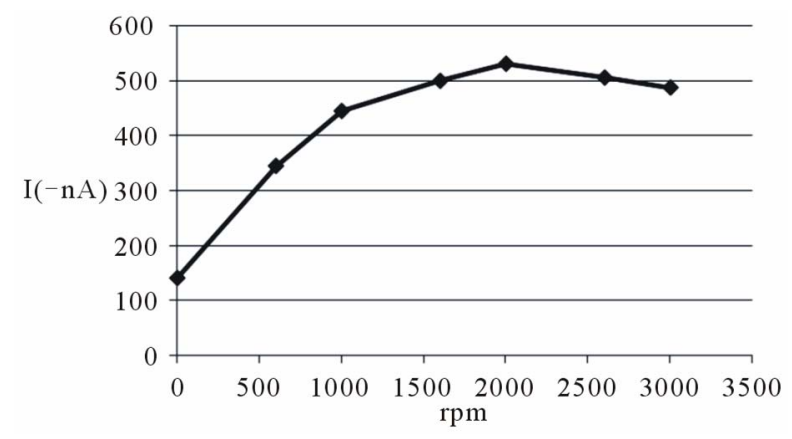

Figure 11. Effect of convection rate on the peak current of 1 $\times 10^{-6} \mathrm{M}$ Timolol in pH 3.5 Acetate buffer, accumulation time $30 \mathrm{sec}$, accumulation potential $-0.8 \mathrm{~V}$, Scan rate 250 $\mathrm{mV} / \mathrm{s}$, pulse amplitude $0.10 \mathrm{~V}$, frequency $15 \mathrm{~Hz}$ and drop size $0.6 \mathrm{~mm}^{2}$.

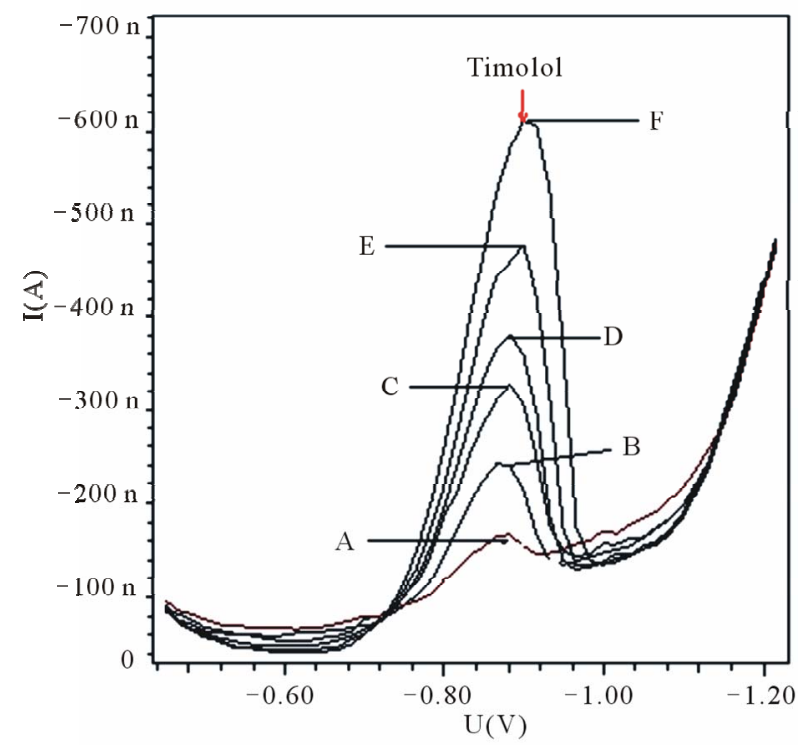

Figure 12. SW-AdSV voltammogram for Timolol in acetate buffer, $\mathrm{pH}=3.5, T_{a c c}=30 \mathrm{sec}, E_{a c c}=-0.80 \mathrm{~V}$. Drug Conc.:$\left(\mathrm{A}=1 \times 10^{-7} \mathrm{M}, \mathrm{B}=3 \times 10^{-7} \mathrm{M}, \mathrm{C}=5 \times 10^{-7} \mathrm{M}, \mathrm{D}=7 \times 10^{-7}\right.$ $\left.\mathrm{M}, \mathrm{E}=1 \times 10^{-6} \mathrm{M}, \mathrm{F}=1.5 \times 10^{-6} \mathrm{M}\right)$. Drug Conc.: $(\mathrm{A}=1 \times$ $10^{-7} \mathrm{M}, \mathrm{B}=3 \times 10^{-7} \mathrm{M}, \mathrm{C}=5 \times 10^{-7} \mathrm{M}, \mathrm{D}=7 \times 10^{-7} \mathrm{M}, \mathrm{E}=$ $\left.1 \times 10^{-6} \mathrm{M}, \mathrm{F}=1.5 \times 10^{-6} \mathrm{M}\right)$.

Least-square treatment of the calibration graph yielded the following regression equation:

$$
i_{p}(\mathrm{nA})=53.1+3.1 \times 10^{8} \mathrm{C}\left(\mathrm{mol} \mathrm{l}^{-1}\right) \quad \mathrm{r}=0.998, \mathrm{n}=6 .
$$

where $i_{p}$ is the adsorptive stripping peak current, $\mathrm{C}$ is the analysed drug concentration and $r$ is the correlation coefficient.

\subsubsection{Detection Limit}

The lowest detectable concentration of this drug was $1.26 \times 10^{-9} \mathrm{~mol} \cdot \mathrm{l}^{-1}(0.4 \mathrm{ppb})$, which was estimated based on the signal-to-noise ratio $(\mathrm{S} / \mathrm{N}=3)$ and this obtained analytical sensitivity is very promising since it was achieved after employing very short accumulation time
(30 s) comparing to that reported for the previous voltammetric determination of timolol using differential pulse voltammetry (DPV) technique which required $2.5 \mathrm{ppb}$ detection limit [23].

\subsubsection{Reproducibility}

The high sensitivity of adsorptive voltammetry is accompanied by very good reproducibility. This analytical performance was evaluated from eight repeated measurements of electrochemical signal of $1 \times 10^{-6} \mathrm{~mol} \cdot 1^{-1}$ timolol drug solution. The precision of the electrochemical developed method in terms of the relative standard deviation $(\mathrm{RSD} \%)$ was $0.13 \%$.

\subsubsection{Accuracy}

The accuracy of the proposed method was checked by calculating the recovery of known amount of timolol $(5 \times$ $10^{-7} \mathrm{~mol} \cdot \mathrm{l}^{-1}$ ) solution added to acetate buffer solution and analysed via the optimized stripping voltammetric procedure. The value of the recovery obtained by the standard addition method was $110 \% \pm 1.414$.

\subsubsection{Stability}

Under the optimum conditions, the stability of $1 \times 10^{-6}$ $\mathrm{mol} \cdot \mathrm{l}^{-1}$ timolol solution was evaluated by monitoring the changes in the height of adsorptive stripping voltammetric (AdSV) peak over a period of $90 \mathrm{~min}$. The electroanalytical signal was gradually constant with time. The acidic media ( $\mathrm{pH} 3.5)$ of the acetate electrolyte solution probably initiated a slow degradation process for the drug.

\subsection{Interference Studies}

In order to evaluate the selectivity of the developed AdSV procedure, the influence of various interferences was examined. Considerable interference can be caused by co-existing surface-active compounds capable of competing with the analyte of interest for the adsorption site on the electrode surface, resulting in decreased or increased peak height. The competitive co-adsorption interference was evaluated in the presence of various substance usually occur in the pharmaceutical eye-drops and formulations. For these investigations, the interfering species were added at different concentrations (one, 5 -fold and 50-fold) higher than the concentration of timolol $\left(1 \times 10^{-6} \mathrm{~mol} \cdot \mathrm{l}^{-1}\right)$. The addition of starch at these concentration levels caused the adsorptive stripping voltammetric (AdSV) peak current to decrease by about $3 \%$, $4 \%$ and $6 \%$, respectively, of its original peak current. Also the addition of 50 -fold of sucrose in the test drug solution $\left(1 \times 10^{-6} \mathrm{~mol} \cdot \mathrm{l}^{-1}\right)$, caused the stripping voltammetric peak current to decrease by about $8 \%$. Apparently, 
these inhibition effects were caused by the working electrode surface blockage due to adsorption of interferences. In contrast, the addition of 50 -fold of lactose in the drug solution, caused the square wave adsorptive stripping voltammetry (SW-AdSV) response of the drug to increase by about $16 \%$.

\subsection{Practical Applications}

The reliability of the proposed adsorptive stripping voltammetry (AdSV) method for the determination of timolol drug was investigated by assaying this drug in some real samples. Following the developed electroanalytical procedure described above, timolol drug was analysed in pharmaceutical formulation. The timolol content of commercially available eye drop (Ocumol 0.5, Timolol $0.5 \%, 5 \mathrm{mg} / \mathrm{ml}$ ) was determination directly by the square wave adsorptive stripping voltammetry (SWAdSV) method after the required dissolving steps. Four aliquots of the dissolved sample were diluted to the required concentration level and measured via the standard additions approach. For these studies, results obtained gave a recovery mean $80 \%$ with standard deviation of \pm 2.94\%. As can be seen from Table 1 (Analysis of Timolol drug in its commercial eye drop).

In addition, the applicability of the stripping voltammetric procedure for the analysis of timolol drug in biological samples was also evaluated by estimating its recoveries from spiked human urine and serum samples. A simple and fast pretreatment (clean-up) procedure, which is in fact a slight modification of the sample preparation method develop for the determination of some antagonist drugs [25] was used. By adding a small amount of 5\% $\mathrm{ZnSO}_{4} \cdot 7 \mathrm{H}_{2} \mathrm{O}$ solution, $\mathrm{NaOH}$ and methanol to the serum sample and centrifuging the mixture, most of the interfering substances (mainly proteins) were simply removed and eliminated by precipitation. As can be extracted from Table 2 (Analytical results for timolol drug recoveries from urine and serum samples), this adsorptive stripping voltammetric (AdSV) method (after appropriate dilution) allowed the determination of timolol drug in urine and

Table 1. Analysis of Timolol drug in its commercial eye drop.

\begin{tabular}{ccc}
\hline & Found (mg) & Recovery \% \\
\hline Labeled & 3.85 & 77 \\
Content & 3.90 & 78 \\
$\mathbf{5} \mathbf{~ m g / m l}$ & 4.10 & 82 \\
Timolol & 4.15 & 83 \\
& Mean & 80 \\
& Standard Deviation & \pm 2.94 \\
\hline
\end{tabular}

Table 2. Analytical results for timolol drug recoveries from urine and serum samples.

\begin{tabular}{ccc}
\hline Recovery\%: & Spiked Urine & Spiked Serum \\
\hline & 86 & 108 \\
Added Timolol & 88 & 107 \\
$\mathbf{5 . 0} \times \mathbf{~ 1 0}^{-7}{\mathbf{~ m o l} \cdot \mathbf{l}^{\mathbf{1}}}^{\mathbf{1}}$ & 85 & 109 \\
Means $_{\text {Standard Deviations }}$ & 87 & 106 \\
\hline
\end{tabular}

serum samples with mean recoveries $87 \% \pm 1.83$ and $107.5 \% \pm$ kmi 1.3 , respectively.

\section{Conclusions}

Voltammetric methods have proved to be very sensitive for the determination of organic molecules, including drugs and related molecules in pharmaceutical dosage forms. These techniques have several advantages, including that they are quick and reproducible, present low limits of detection and quantification and have relatively low cost compared with the more traditional techniques. Moreover, they provide a better discrimination against background currents.

In this study, a new, simple, selective, accurate and precise SW-AdSV method developed for the determination of Timolol in pharmaceutical formulation. In this study, all experimental and instrumental parameters were optimized, as their values strongly affect the sensitivity of the voltammetry. The peak current was investigated using differential pulse polarography and cyclic voltammetry. The electrochemical reduction of Timolol is an irreversible process controlled by adsorption under the conditions described in this work. The proposed method with the optimized parameters demonstrated a good linear relationship between the peak current and the Timolol concentration for a wide range of concentration. The applicability of the proposed procedure was tested using a commercial pharmaceutical formulation of Timolol. This drug was quantified in the pharmaceutical preparation and biological fluids such as serum and urine, and no pretreatment or time - consuming extraction was required prior to the analysis. The results are in good agreement with the labeled values. Accuracy and selectivity of the developed method were demonstrated by recovery studies. Reproducibility, stability, and interferences studies of this proposed method suggest that this method could be used in quality control analysis, clinical laboratories, and pharmacokinetic studies. 


\section{Acknowledgements}

I would like to thank Prof. Mohammed Hefnawy and Prof. Mohammed Al-Omar at King Saud University for their assistances.

\section{References}

[1] J. Wang, "Analytical Electrochemistry," 2nd Edition, VCH Publishers, Inc., New York, 1994, pp. 44-54.

[2] K. H. Brainina and E. Neyman, "Electroanalytical Stripping Methods," John Wiley and Sons, New York, 1993, pp. 71-120.

[3] J. Wang, "Stripping Analysis: Principles, Instrumentation and applications," VCH Publishers Inc., New York, 1985, pp. $1-160$

[4] R. Kalvoda, "Adsorptive Stripping Voltammetry in Analytical Chemistry II," Ellis Horwood, New York, 1996.

[5] J. Wang, "Electroanalytical Techniques in Clinical Chemistry and Laboratory Medicine," VCH Publishers Inc., New York, 1988, pp. 17-20.

[6] P. M. Zaitsev, R. M. Salikhdzhanova and N. K. Zaitsev, "Use of Adsorption Voltammetry in Trace Analysis of Inorganic Ions," Industrial Laboratory, Vol. 65, No. 1, 1999, pp. 1-15.

[7] A. Z. Abu Zuhri and W. Voelter, "Applications of Adsorptive Stripping Voltammetry for the Trace Analysis of Metals, Pharmaceuticals and Biomolecules," Fresenius' Journal of Analytical Chemistry, Vol. 360, No. 1, 1998, pp. 1-9. doi:10.1007/s002160050633

[8] K. H. Brainina, N. A. Malakhova and N. Y. Stojko, "Stripping Voltammetry in Environmental and Food Analysis," Fresenius' Journal of Analytical Chemistry, Vol. 368, No. 4, 2000, pp. 307-325. doi:10.1007/s002160000525

[9] N. S. Abdul, S. Afzal, A. M. Sarfraz and R. Abdul, "Adsorptive Stripping Voltammetric Determination of Hydroquinone Using an Electrochemically Pretreated Glassy Carbon Electrode," Pakistan Journal of Analytical Environmental Chemistry, Vol. 9, No. 2, 2008, pp. 110-117.

[10] A. H. Alghamdi, "Square-Wave Adsorptive Stripping Voltammetric Determination of an Antihistamine Drug Astemizole," Chemical Papers, Vol. 62, No. 4, 2002, pp. 339-344.

[11] J. C. Vire, J. M. Kauffmann and G. J. Patriarche, "Adsorptive Stripping Voltammetry Applied to Drug Analysis: A Powerful Tool," Journal of Pharmaceutical and Biomedical Analysis, Vol. 7, No. 12, 1998, pp. 13231335.

[12] M. M. Ghoneim, A. M. Beltagi and A. Radi, "SquareWave Adsorptive Stripping Voltammetric Determination of the Anti-Inflammatory Drug Lornoxicam," Analytical Sciences, Vol. 18, No. 2, 2002, p.183.

[13] O. A. Farghaly, "Adsorptive Stripping Voltammetric Determination of the Antidepressant Drug Sulpiride," Journal of Pharmaceutical and Biomedical Analysis, Vol.
23, No. 5, October 2000, pp. 783-791. doi:10.1016/S0731-7085(00)00376-9

[14] A. H. Alghamdi, M. A. Alshadokhy and A. A. Alwarthan, "Development of Adsorptive Stripping Voltammetric Procedure for the Determination of Josamycin, a Macrolide Antibiotic," Jordan Journal of Chemistry, Vol. 1, No. 2, 2006, pp. 171-182.

[15] B. Susan, "The Merck Index," 12th Edition, Whitehouse Station, Merck\& Co., Inc., New Jersey, 1996.

[16] E. F. K. James, "Matrindale the Extra Pharmacopoeia," 31st Edition, Royal Pharmaceutical Society, London, 1996.

[17] M. M. Ayad, A. Shalaby, H. E. Abdellatef and M. M. Hosny, "Spectrophotometric Methods for Determination of Enalapril and Timolol in Bulk and in Drug Formulations," Analytical and Bioanalytical Chemistry, Vol. 375, No. 4, 2003, pp. 556-560.

[18] S. P. Agarwal, V. Singhal and A. Prakash, "Spectrophotometric Determination of Atenolol and Timolol Dosage forms via Charge-Transfer Complexation," Indian Journal of Pharmaceutical Science, Vol. 60, No. 1, 1998, pp. 53-55.

[19] M. L. Sataf, J. Robles, H. C. Goicoechea and A. C. Olivier, "Simultaneous Determination of Timolol Maleate and Pilocarpine Hydrochloride in Ophthalmic Solutions by First Derivative UV Spectrophotometry and PLS-1 Multivariate Calibration," Analytical Letters, Vol. 32, No. 10, 1999, pp. 2019-2033. doi: $10.1080 / 00032719908542949$

[20] S. P. Kulkarni and P. D. Amin, "Stability Indicating HPTLC Determination of Timolol Maleate as Bulk Drug and in Pharmaceutical Preparations," Journal of Pharmaceutical and Biomedical Analysis, Vol. 23, No. 6, 2000, pp. 983-987. doi:10.1016/S0731-7085(00)00389-7

[21] T. V. Olah, J. D. Gilbert and A. Barrish, "Determination of the $\beta$-Adrenergic Blocker Timolol in Plasma by Liquid Chromatography-Atmospheric Pressure Chemical Ionization Mass Spectrometry," Journal of Pharmaceutical and Biomedical Analysis, Vol. 11, No. 2, 1993, pp. 157-163.

[22] H. B. He, I. E. Timi and J. J. Alastrair, "Determination of Low Plasma Timolol Concentrations Following Topical Application of Timolol Eye Drops in Humans by High-Performance Liquid Chromatography with Electrochemical Detection," Journal of Chromatography B: Biomedical Science Applications, Vol. 661, No. 2, November 1994, pp. 351-356.

[23] M. H. Urkdemir, G. Erdogdu, T. Aydemir, A. A. Karagozler and A. E. Karagozler, Journal of Analytical Chemistry, Vol. 56, 2001, pp. 1047-1050.

[24] C. M. Van den Berg, "The Determination of Nanomolar Levels of Nitrite in Fresh and Sea Water by Cathodic Stripping Voltammetry," Analytical Chemica Acta, Vol. 212, 1988, pp. 31-41.

[25] G. Stubauer and D. Obendorf, "Determination of Trace Levels of Niguldipine in Urine and Blood by Adsorptive Stripping Voltammetry at the Hanging Mercury Drop Electrode," Analyst, Vol. 121, No. 3, 1996, pp. 351-356. 